\section{O ENSINO DE LÍNGUA LATINA NO BRASIL: PERCURSO E PERSPECTIVAS ${ }^{1}$}

\author{
Leni Ribeiro Leite*
Marihá Barbosa e Castro**
}

RESUMO: Com base em estudos anteriores sobre o desenvolvimento do ensino básico e superior no Brasil, e como primeira etapa de um estudo mais amplo acerca das propostas e perspectivas do ensino de língua latina no Brasil, este trabalho procurou traçar um panorama do ensino de línguas clássicas, em especial da língua latina no Brasil, desde o período colonial, buscando compreender os movimentos que levaram à situação atual, em que a língua latina ocupa espaço mínimo nos currículos universitários, em geral apenas dos cursos de Letras. Em seguida, procurou-se esboçar o quadro atual dos debates na área do ensino de língua latina na universidade brasileira, apontando-se os principais desafios enfrentados pelos pesquisadores da área.

\section{LATIN TEACHING IN BRAZIL: PATHS AND PERSPECTIVES}

PALAVRAS-CHAVE: Ensino superior; Ensino de línguas; Latim.
1. Esta pesquisa tem o apoio da Fundação de Amparo à Pesquisa do Espírito Santo (FAPES).

* Professora da Universidade Federal do Espírito Santo

** Mestranda da Universidade Federal do Espírito Santo

\begin{abstract}
Based on previous studies about the development of basic and higher education in Brazil, and as a first step in a wider study about the perspectives of Latin teaching in Brazil, this article aims at drafting a picture of the teaching of Classical Languages, with special attention to Latin, in Brazil, since the colonial period, trying to understand the movements that led to the current situation, in which Latin has minimal space in the curricula in universities, in general only within the languages and literature majors. After that, a picture of the current debates in the area has been drawn, pointing out the main challenges faced by teachers and researches of Latin teaching in Brazilian universities.
\end{abstract}

KEYWORDS: Higher education; language teaching; Latin. 
2. Para um panorama detalhado da permanência e uso do latim nos períodos medieval e renascentista, cf. IJSEWIJN (1990); OSTLER (2007: 190259); SOLODOW (2010: 31-55); TUNBERG (2013) entre outros.
INTRODUÇÃO

pós a dissolução do Império Romano Ocidental,
no século V da era cristã, o latim e a cultura clássica
gozaram, ainda por muito tempo, de privilegiado estatuto no mundo intelectual, sendo considerados fundamentais para a formação do homem letrado. Até o século XVIII, o latim estava firmemente estabelecido como língua de cultura, bem como língua oficial da Igreja Católica, o que contribuiu para a manutenção de seu prestígio e difusão. Portanto, apesar de não mais haver falantes nativos de latim, o idioma permaneceu em constante uso pelos religiosos, filósofos, cientistas muito depois do desaparecimento da civilização que o criou. $^{2}$

Debater os motivos pelos quais o latim veio a ocupar tal papel no cenário intelectual, cultural e literário do mundo ocidental durante tão longo período - pode-se considerar que apenas no fim do século XIX e primeira metade do século XX os estudos clássicos sofreram decisivo declínio no ensino básico e superior no Brasil e em outras partes do mundo - é uma tarefa extensa que nos faria perder de vista o principal objeto deste trabalho: o ensino de latim no Brasil, do período colonial até o século XXI, com seus desafios e perspectivas. Deter-nos-emos, portanto, apenas na breve exposição da trajetória do latim nos currículos da educação brasileira e, sobretudo, nas mudanças que culminaram na supressão do latim como disciplina obrigatória no ensino básico a partir da LDB de 1961.

\section{RATIO STUDIORUM}

A história do ensino de latim no Brasil começa com a chegada dos padres da Companhia de Jesus, em 1549, na expedição de Tomé de Souza, que marca o início das iniciativas educacionais dos colonizadores. A Companhia de Jesus, criada em 1539 por Inácio de Loyola, surgiu durante o período em que a Igreja Católica empenhava seus esforços na contrarreforma, resposta aos eventos de dissidência, perda de hegemonia e de domínio religioso em algumas regiōes da 
Europa durante os séculos XVI e XVII. A ordem foi reconhecida em 1540 pelo Papa Paulo III e a princípio possuía poucos membros. De acordo com a primeira legislação, a ordem só poderia ter no máximo 60 membros, mas sua grande popularidade fez com que essa limitação fosse revogada, e, em poucos anos, a Companhia de Jesus estava em toda parte, inclusive nas colônias espanholas e portuguesas no continente americano, onde realizava missões de evangelização e propagação da fé (SHIGUNOV NETO; MACIEL, 2008: 171). A catequização dos índios tornou-se um dos principais objetivos dos jesuítas no Brasil, onde a Companhia de Jesus servia concomitantemente aos interesses da Coroa e do Papado, através de ações combinadas para "expandir o mundo, defender as novas fronteiras, somar forças, integrar interesses leigos e cristãos, organizar o trabalho no Novo Mundo pela força da unidade lei-rei-fé" (RAYMUNDO, 1999: 43).

Já nos primeiros dias após o desembarque em praias brasileiras, os Jesuítas criaram a primeira escola "de ler e escrever" da colônia. Várias outras se seguiram: em 1556, inauguraram o Colégio de Todos os Santos, em Salvador. Ao longo dos 210 anos em que gerenciaram a educação brasileira, ofereceram todos os níveis de formação para os habitantes da colônia (SHIGUNOV NETO; MACIEL, 2008: 174-176). Seja como disseminadores da fé junto aos gentios, seja como tutores dos governantes do império, os jesuítas tinham como base de sua atuação educacional a Ratio Studiorum, o manual que estabelecia a organização e administração do sistema educacional e o currículo a ser seguido pelos padres professores da Ordem de Jesus. Freire (2008: 180) qualifica o sistema pedagógico dos jesuítas de tradicional e literário: para ele, "o método de ensino utilizado pelos jesuítas era principalmente expositivo, livresco, com pouco ou nenhum sentido prático" (FREIRE, 2008: 181). Dentro desse currículo, o cultivo da língua latina e das humanidades era primordial; os alunos entravam em contato com o latim desde cedo, e era ele não só uma disciplina em si, mas o instrumento através do qual todo conhecimento era transmitido, o veículo de informação e estudo de muitas das demais disciplinas curriculares.

A Ratio Studiorum era um unificador do método da Companhia e, por isso, prescrevia detalhadamente de que 
maneira as aulas de cada disciplina deviam ser ministradas nos vários níveis do ensino, indicando também a postura e abordagem adequadas para os professores e coordenadores dos colégios da Ordem. De certa forma, aquele documento, promulgado em 8 de janeiro de 1599, se aproxima dos documentos hoje norteadores da educação básica brasileira, não no que diz respeito ao conteúdo e preceitos defendidos, mas na medida em que procura balizar as práticas docentes em sala de aula, mantendo a uniformidade do projeto em toda a sua extensão. A formação acadêmica do homem ocidental durante os séculos XVI e XVII era amplamente definida pelo projeto educacional jesuíta, que foi responsável, também, por instruir as camadas menos favorecidas da população europeia e pelo letramento dos indígenas.

Os estudos clássicos e o ensino do latim eram igualmente definidos pela Ratio Studiorum. Essas disciplinas eram ministradas de acordo com uma leitura do mundo clássico filtrada pelos dogmas do cristianismo, construída primeiro pelos Pais da Igreja e, mais tarde, pelos homens letrados do Renascimento. Para exemplificar de que modo esse filtro organizava o ensino de língua e literatura latina, observemos um trecho da Ratio Studiorum:

Que de modo algum se sirvam os nossos, nas aulas, de livros de poetas ou outros, que possam ser prejudiciais à honestidade e aos bons costumes, enquanto não forem expurgados dos fatos e palavras inconvenientes; e se de todo não puderem ser expurgados, como Terêncio, é preferível que não se leiam para que a natureza do conteúdo não ofenda a pureza da alma (FRANCA, 1952: 6).

A proibição em termos de "livros de poetas ou outros" [grifo nosso] neste trecho exemplifica a tendência em afastar a poesia da sala de aula, dando preferência a outras formas literárias, em especial às prosas históricas e aos textos declamatórios. Ainda que tal afirmação possa se aplicar a poetas contemporâneos ao documento, é presumível principalmente quando o único autor citado é romano que essa recomendação fosse a respeito, sobretudo, de autores clássicos que não confirmavam, em suas obras, as virtudes e valores abraçados pela doutrina cristã. Esses valores, 
entretanto, são observados em outras obras, que são por isso recomendadas, tais como os discursos de Cícero. Muitas outras são recomendadas, mas com ressalvas. Quando sugeridas as leituras de outros autores latinos, fica clara a preocupação em selecionar os trechos que não sejam contrários à moralidade cristã, sendo função do mestre expurgar os poemas antes de levá-los às salas de aula: ${ }^{3}$

Para conhecimento da língua, que consiste principalmente na propriedade e riqueza das palavras, explique-se, nas liçōes quotidianas [...] dos poetas, principalmente Virgílio com exceção de algumas éclogas e do 4o. livro da Eneida, odes seletas de Horácio e também elegias, epigramas e outras composiçōes de poetas ilustres, contanto que expurgados de qualquer inconveniência de expressão. (FRANCA, 1952: 38, grifos nossos).

Quanto às leituras, poderão explicar-se no primeiro semestre dos prosadores, as cartas mais importantes de Cícero [...]; dos poetas no primeiro semestre algumas elegias ou epistolas de Ovídio, escolhidase expurgadas, no segundo, trechos, também escolhidos e expurgados, de Catulo, Tibulo, Propércio e das Éclogas de Virgílio, ou ainda, do mesmo Virgílio, os livros mais fáceis como o 4o. das Geórgicas, o 5o. e o 7o. da Eneida (FRANCA, 1952: 41, grifos nossos).

O nome de Cícero, entre os autores romanos, é o mais citado da Ratio Studiorum (35 vezes), sendo amplamente recomendada a sua leitura, análise e imitação para as mais variadas finalidades educativas:

Quanto às regras, ainda que se possam procurar e observar em todas as fontes, não se deve, contudo, explicar, na preleção quotidiana, senão nos livros retóricos de Cícero, na Retórica de Aristóteles, e, se parecer conveniente, também na sua Poética. No que concerne ao estilo, ainda que se devam percorrer os melhores historiadores e poetas, deverá ser formado quase exclusivamente em Cícero; para esse fim se adaptam perfeitamente todos os seus livros, mas as orações deverão ser só explicadas a fim de que nelas se vejam a aplicação dos preceitos da oratória (FRANCA, 1952: 35-36).

a.i.1. O tempo será dividido do seguinte modo. Na primeira hora da manhã recite-se o trecho decorado de Cícero e da arte métrica, tomado pelos decuriōes (FRANCA, 1952: 39).
3. Bastante conhecidas, as ediçóes Ad Usum Delphini ou In Usum Delphini foram um eloquente exemplo deste desejo da manutenção dos textos clássicos latinos como base indispensável da formação do homem educado e instruído, mas limpos de tudo o que afrontasse a fé ou a moral cristãs. Para uma discussão acerca desses textos e sua função pedagógica, $v$.

VOLPILHAC-AUGER (1997). 
a.i.2. Enquanto corrige os trabalhos escritos pode passar algum dos exercícios seguintes: colher frases dos trechos explicados e variá-las de muitas maneiras; reconstituir um período de Cícero que haja sido desarticulado; fazer versos, passar uma poesia de uma para outra forma; imitar um trecho, escrever em grego (ou em vernáculo) e outros semelhantes (FRANCA, 1952:39).

a.i.3. Quanto às leituras, poderão explicar-se no primeiro semestre dos prosadores, as cartas mais importantes de Cícero aos parentes, a Ático, ao irmão Quinto (FRANCA, 1952: 41).

a.i.4. Na segunda hora matutina, repetição breve da última lição de Cícero, explicação por meia hora da nova, que será logo objeto de interrogação, por último, ditado do tema (FRANCA, 1952: 41).

No que diz respeito ao latim, observam-se dois aspectos na educação ministrada pelos jesuítas: (1) há a clara preocupação em incluir a língua e a literatura latina em todos os níveis do ensino, mas (2) essa inclusão se faz de modo interessado, uma vez que os textos antigos eram escolhidos e apresentados para os alunos de acordo com a moralidade cristã; os autores e trechos eram selecionados com o intuito de corroborar os conceitos e ideais valorizados pela Companhia de Jesus e pela Igreja Católica.

A posição ocupada pelo latim no currículo das escolas jesuítas responde diretamente ao uso do latim no mundo letrado europeu do período: àquela altura, o latim já se desprendera do mundo clássico e já há muito não era mais a língua que representava apenas o povo, a cultura e a literatura romanos. Todos os demais povos europeus tinham dele se apropriado e utilizado como sua própria língua, e isso se vê refletido no currículo jesuítico, que usa o latim não só na recuperação dos elementos da cultura clássica, mas principalmente como veículo de expressão do pensamento e cultura europeus contemporâneos. Em suma, o papel do ensino de latim neste modelo era central e se fazia não só pelo resgate e manutenção de elementos clássicos da antiguidade, mas dava à língua latina o lugar de principal veículo de transmissão da realidade coeva e do pensamento cristão e leigo.

Embora possamos analisar as formas pelas quais os jesuítas se apropriaram da cultura e da literatura clássicas para construir seu currículo como tendenciosas e 
programáticas, é inegável que a educação jesuítica se caracterizava pela formação de caráter humanista, ou seja, que considerava como mais importantes a dignidade humana, a cultura e a arte, colocando em segundo plano o pragmatismo do ensino, ou seja, a formação voltada para o trabalho, tão caro aos debates sobre educação nos séculos vindouros, como demonstra a afirmação de Freire citada acima, que acusa a formação jesuítica de ter "pouco ou nenhum sentido prático".

\section{AS REFORMAS POMBALINAS E $O$ VERDADEIRO MÉTODO DE ESTUDAR}

A educação jesuítica vigorou durante dois séculos no Brasil e em muitas outras partes do mundo; entretanto, o poder acumulado pela Companhia de Jesus durante aqueles mesmos dois séculos era visto como ameaça à soberania de muitos países e até mesmo da própria Igreja. Os jesuítas sofreram, ao longo do século XVIII, diversas retaliações: foram expulsos da França em 1764; da Espanha, em 1767; em Portugal, o Marquês de Pombal, através do Alvará de 18 de junho de 1759, oficializou o fim da educação ministrada pela Companhia de Jesus em todas as regiōes do império, expulsando-os das terras portuguesas. Em 1773, o Papa Clemente XIV decretou a supressão da Companhia de Jesus. ${ }^{4}$

A expulsão dos jesuítas foi crucial para a educação brasileira: desde a sua chegada, os inacianos tinham detido a responsabilidade pela quase totalidade das instituições de ensino. Ao expulsar os jesuítas, o Marquês de Pombal baniu praticamente todos os professores da colônia. Pombal, amplamente influenciado pelos ideais iluministas, pretendia substituir a organização eclesiástica do ensino por uma metodologia laica (MACIEL; SHIGUNOV NETO, 2006: 470). Para tanto, o rei D. José instaurou, através do Alvará de 1759, o sistema de aulas régias, de modo que fosse possível não só

lutar contra a decadência dos estudos, 'mas restituir-lhes aquele antecedente lustre que fez os portugueses tão conhecidos na república das letras'. Ainda segundo o Alvará, o ensino jesuítico
4. Sobre a história da Companhia de Jesus no Brasil e no mundo, v. PEDRO (2008) e BANGERT (1985). 
havia interrompido a tradição do humanismo quinhentista, que agora precisava ser restaurado. (ALMEIDA, 2001:73).

O verdadeiro método de estudar (1746), de Verney, foi a mais importante obra do período cujas proposições guiaram as reformas pombalinas. Verney postulava o ensino de literatura através do português, do latim, da retórica e da poética. Embora possa parecer que a proposta de Verney pouco se diferenciasse do currículo jesuíta, as disciplinas, ainda que as mesmas, têm função diversa. A retórica, por exemplo, se mantinha no currículo não apenas para ensinar os alunos a bem usar a palavra nas relações com outros seres humanos ilustrados, mas cumprindo a função de armamento na batalha da construção das novas representações do reino português, que queria deixar a velha imagem de reino cristão em favor de uma mais moderna, de nação europeia polida e civilizada. Quanto ao ensino de latim, o autor faz muitas críticas ao modo ineficaz por que os jesuítas o ensinavam, ocupando muito tempo com memorização de regras gramaticais, mas dedicando pouco à leitura e a exercícios que poderiam oferecer ao aluno um domínio ativo do idioma. Essa tensão proposta $\mathrm{n} O$ verdadeiro método de estudar já prenuncia uma dicotomia com a qual os professores de latim ainda hoje precisam lidar: aquela que contrapõe o estudo centrado em processos gramaticais aos métodos de leitura. É interessante observar que Verney acusava o método jesuíta de ineficaz porque resultava em alunos que, ao cabo de anos de estudo, não conseguiam ler o latim com fluência - uma observação que ecoa em discussões hodiernas sobre o ensino do idioma.

Verney propunha reformas que estivessem alicerçadas no estudo da Antiguidade Clássica, de forma que os estudantes se percebessem unidos à tradição e à cultura clássicas. $\mathrm{O}$ autor defendia que somente através dos textos dos grandes autores latinos os jovens poderiam compreender e conhecer a cultura clássica e, para isso, o estudo do latim era necessário. Ao confrontarmos o ensino de latim dos jesuítas e o proposto por Verney, percebemos a diferença no modo como cada uma dessas orientaçôes pedagógicas enxergava o latim: 
O latim dos jesuítas era ensinado e empregado como uma língua universal, viva e falada no seio da Igreja. Já o ensino da língua latina proposto pela reforma terá um caráter totalmente diverso, na medida em que o latim será encarado como língua morta, deixando de ser uma língua falada para ser valorizada como herança. E, por isso, o ensino do latim impõe-se, obrigatoriamente, na língua materna, com a proibição, pelo menos nos primeiros anos, de se falar latim nas aulas. (ALMEIDA: 2001, 76)

Interessa-nos atentar para o fato de que a acusação de Verney, de que os jesuítas ensinavam gramática e, portanto, os alunos dos jesuítas não eram proficientes na língua latina, parece ir de encontro ao propósito do ensino jesuíta, ou seja, de que o latim era língua viva e, portanto, falada, ouvida, lida, escrita. Por outro lado, o método de Verney, ao menos em teoria, busca uma proficiência na leitura e, portanto, se aproximaria dos métodos modernos que propõem o latim como língua viva; no entanto, ao enfatizar a importância dos clássicos como tradição, relega-lhe o papel de língua morta e, portanto, não falada, não escrita. Há uma quase inversão em relação ao que o mundo moderno entenderá em termos de métodos de ensino de latim, uma vez que, no século $\mathrm{XX}$, como veremos, os métodos que propõem o ensino de gramática em geral não se conjugam com o ensino de latim como língua viva, e sim como leitura, apenas.

Almeida (2001) observa que o método de Verney estava ancorado no princípio lockiano de utilidade da cultura, já um passo distante das propostas humanistas de ornamentação do espírito. Assim,

Os estudos superiores deveriam ser ajustados às necessidades culturais de Portugal, e os estudos menores à sua função de preparatório para a universidade, para que resultasse em "uma maior eficiência ou utilidade, dos homens formados pela universidade" (ALMEIDA, 2001: 74).

Há ainda uma outra diferença fundamental entre a educação jesuítica e a proposta pombalina que também já prefigura uma importante arena de combate do século XX: a laicização do ensino. A nova proposta, ao enxergar a educação como um espaço do saber laico, se afasta da concepção jesuíta do ensino, e a apropriação dos textos 
clássicos terá, decerto, outra conotação. Entretanto, por mais sedutoras que possam parecer as ideias de Verney, não houve, ao menos no Brasil, a concretização de tais ideais. Maciel e Shigunov Neto destacam que

\begin{abstract}
A reforma de ensino pombalina pode ser avaliada como sendo bastante desastrosa para a Educação brasileira e, também, em certa medida para a Educação em Portugal, pois destruiu uma organização educacional já consolidada e com resultados, ainda que discutíveis e contestáveis, e não implementou uma reforma que garantisse um novo sistema educacional (MACIEL; SHIGUNOV NETO, 2006: 475).
\end{abstract}

$\mathrm{Na}$ prática, as propostas da reforma pombalina para a educação provocaram a desorganização da educação na colônia, criando um hiato de quase meio século em que se podem observar tentativas frustradas de aplicar aquilo que havia sido concebido teoricamente pelo alvará de 1759. A expulsão dos jesuítas, muito longe de resolver as questões do currículo educacional, criou uma situação caótica em que uma educação regular e consolidada foi substituída pela ausência de um sistema educacional. Maciel e Shigunov Neto concluem que, no Brasil,

não há uma continuidade nas propostas educacionais implantadas. A expulsão dos jesuítas e a total destruição de seu projeto educacional podem ser consideradas como o marco inicial dessa peculiaridade tão arraigada na Educação brasileira (MACIEL; SHIGUNOV NETO, 2006: 472).

Apenas depois de dezesseis anos da expulsão dos jesuítas, as primeiras escolas com cursos graduados e sistematizados foram instituídas. Isso não significou, decerto, uma pronta laicização do ensino, ainda que tenha sido um passo nessa direção. No entanto, a própria inexistência de professores desvinculados de instituições religiosas foi um impedimento, e, na ausência dos jesuítas, outras congregações - beneditinos e franciscanos, principalmente - passaram a atuar como educadores. Por isso, as funções de padre e professor estiveram, ainda por muito tempo, amplamente associadas. 


\section{SÉCULO XIX E A CHEGADA DA FAMÍlIA REAL}

O momento seguinte de transformação na educação brasileira se deu já no início do século XIX, a partir da chegada e instalação da família real portuguesa na colônia, que alcançou então o estatuto de reino unido. Cursos de diversas áreas, até então inexistentes, foram criados (BOAVENTURA, 2009: 130). A presença da corte portuguesa criou uma demanda de certas especialidades e profissões, fazendo com que muitos investimentos fossem empreendidos na inauguração de cursos que suprissem as novas necessidades. Antes da chegada da família real, por exemplo, havia pouquíssimos médicos formados na colônia, sendo a falta de profissionais da área da saúde a motivação para a criação de diversos cursos de Medicina. Portugal enfrentava a iminência da guerra contra Napoleão e precisava se estruturar belicamente para promover a defesa militar da Colônia: para isso, criaram-se as Academias Militar e de Marinha, cujo objetivo era "a formação de hábeis oficiais de artilharia, de Engenharia, geógrafos e topógrafos com emprego administrativo nas minas, nos caminhos, portos, canais, pontes, fontes e calçadas, estabelecendo, dessa maneira, a Academia Real Militar" (BOAVENTURA, 2009: 134). Os currículos desses novos cursos e das escolas militares contemplavam áreas do saber de mais recente prestígio, como a matemática e a física, mas negligenciavam o antes onipresente estudo das humanidades. A título de ilustração, o currículo da Academia Militar do Largo de São Francisco de Paula, no Rio de Janeiro, era organizado da seguinte forma:

No $1^{\circ}$ ano, tinha Álgebra, Análise Geométrica, Trigonometria Retilínea e Desenho de Figura; no 2o, Álgebra, Cálculo Diferencial e Integral e Geometria Descritiva; no $3^{\circ}$, Mecânica, Hidráulica e Desenho de Paisagem; no $4^{\circ}$, Trigonometria Esférica, Ótica, Astronomia, Geodésia e Física; no 5º, Tática, Fortificação de Campanha, Química, Filosofia Química e Desenho Militar; no $6^{\circ}$, entravam Ataque e Defesa das Praças e Mineralogia; no sétimo, Artilharia, Zoologia, Desenhos e Máquinas de Guerra e outras matérias. Tudo isso e mais os exercícios práticos, línguas francesa e inglesa e esgrima. (BOAVENTURA, 2009: 134). 
Como se pode observar, a ausência das humanidades é quase total, com a honrosa exceção das línguas francesa e inglesa. As línguas clássicas e as literaturas, antes elementos centrais da educação, estão absolutamente fora do escopo do curso que tem como objetivo formar homens que atuarão em posições de destaque no reino. O ensino de cunho profissionalizante, em várias carreiras, passou a ser valorizado e, além da instituição das cadeiras de Ciências Econômicas e de Química, foram criados a Aula de Comércio e o curso de Agricultura, em Salvador, na Bahia. Os únicos cursos de humanidades que o governo instituiu foram aulas de línguas vivas, que se consideravam úteis por suas possibilidades de uso imediato no contato com aliados estrangeiros.

Ao menos teoricamente, muitos esforços foram feitos durante esse período para suprir demandas educacionais há muito negligenciadas na colônia, mas, dos diversos investimentos feitos, poucos beneficiaram o ensino de humanidades. Nesse momento, o ensino das línguas clássicas começa um movimento de entrincheiramento, sendo primeiro relegado a nichos, reservado aos que decidiam por uma carreira voltada para as humanidades, tal como o Direito, e enfim sumindo dos currículos gerais. Esse também é o momento do declínio de disciplinas antes consideradas nucleares, tais como a Filosofia e a Retórica - esta última, tendo sumido completamente como curso e mesmo como área do conhecimento durante a maior parte dos séculos XIX e XX.

\section{ENSINO NA REPÚBLICA: "BATALHA PELO HUMANISMO"}

A partir da proclamação da República, outras necessidades vieram se somar: os ideais igualitários trazidos do estrangeiro, em especial da França e dos Estados Unidos, estabeleciam como dever do estado a oferta de ensino público e gratuito para todos, e a demanda por escolas e professores aumentou severamente. Intensificou-se o debate sobre o que deveria ser oferecido como formação à juventude do século XX (SOUZA, 2009: 74). Principalmente a partir da década de 1920, vários intelectuais se posicionaram a favor de uma remodelação do currículo das escolas básica e 
secundária, de forma que ela melhor servisse "à sociedade moderna". Os ataques aos conteúdos das áreas de humanidades presentes nos currículos se dirigiam com maior frequência para a questão da utilidade e necessidade dos estudos clássicos, do latim e do grego, embora praticamente todo o ensino de humanidades estivesse sendo contestado (SOUZA, 2009:73). Durante os diversos atos desta "batalha pelo humanismo", argumentava-se, por um lado, que as mudanças nos currículos eram necessárias para que a escola se adaptasse ao novo perfil do alunado - para quem a escola era ponte para o mercado de trabalho -, por outro, que a manutenção do currículo humanista oferecia ao aluno uma formação geral, mais completa, e não apenas uma formação profissional, restrita a uma especialização.

Um currículo pautado nas humanidades defendia a formação de alunos que aprendessem sobre cidadania, moral, valores, virtudes, artes e literatura nas escolas. Os que se alinhavam com este ponto de vista propunham, em geral, a manutenção do estudo do latim como língua da civilização e da cultura. Ainda segundo Souza, para esses educadores "o valor da educação secundária estava no seu acentuado desinteresse, isto é, seu apreço por uma formação geral sem preocupação com a especialização ou a formação profissional” (SOUZA, 2009: 75). Tendo sido construído com base em uma argumentação que valorizava o conhecimento por si e uma formação geral que, ao invés de apontar uma direção desde cedo, nutrisse cidadãos a quem uma formação moral e cultural amplas proporcionassem um maior leque de possibilidades mais tarde, o currículo de vocação humanista estava fadado ao desapreço por parte dos que viam como premente a preparação de profissionais aptos ao trabalho, prontos a carregar sobre os ombros as diversas tarefas pragmáticas da república.

Nem todas as disciplinas de cunho humanista sofreram o mesmo destino: segundo Souza, "disciplinas como História e Geografia, por exemplo, floresceram no início do século XX consolidando uma presença significativa nos programas do secundário" (SOUZA, 2009: 76). Isso se deu por conta da própria construção argumentativa da defesa dessas disciplinas como áreas do saber científicas, de cunho pragmático e necessárias para o desenvolvimento do ser 
5. Ainda que esteja além do escopo deste trabalho, é interessante observar como essas outras áreas das humanidades, em particular a História, desenvolveram como mecanismo de autodefesa uma imagem de áreas próximas às ciências exatas. Segundo F. Hartog, por exemplo, a historiografia do século XIX, "interpretava a História como uma ciência cujo objeto está tão claramente definido quanto o de qualquer outra ciência" (HARTOG, 2003: 337) humano, promovida pelos que construiriam assim sua permanência nos cursos e no apreço da sociedade. ${ }^{5} \mathrm{~A}$ batalha maior se travava em relação à permanência ou não dos estudos clássicos no currículo, uma vez que essas disciplinas eram vistas como ornamento.

Nesse momento, alguns setores vinculados à Igreja Católica saíram em defesa das humanidades, em geral, e mais especificamente da manutenção do ensino do latim. No entanto, uma visão de humanismo enraizada no cristianismo era cada vez mais rejeitada: o humanismo cristão passou a representar uma cultura de privilegiados que se opunha à expressão de uma sociedade democrática, postura que fez com que essas disciplinas ganhassem ainda mais descrédito dos educadores que discutiam as reformas necessárias para os currículos. Essa associação entre catolicismo e estudos clássicos, que foi certamente uma das responsáveis pela forte presença do Latim e do Grego quando o domínio da Igreja sobre a educação era quase absoluto, também contribuiu com o declínio dessas disciplinas no momento em que o Estado e os serviços por ele oferecidos tendiam para um processo de laicização.

Observe-se porém que a discussão sobre a permanência dos estudos clássicos no currículo raramente se preocupou em redimensionar a maneira como essas disciplinas eram ministradas no ensino secundário, de modo que pudessem oferecer aos alunos maior contribuição em sua formação. A forma como o latim vinha sendo ofertado nos currículos básicos e secundários ainda era devedora do Método de Verney que, como vimos, entendia o latim como língua morta, e, como demonstram livros didáticos da época, privilegiava a gramática e a repetição - aquilo que Verney havia, na teoria, combatido, mas que, na prática, havia se mantido como ponto fulcral do ensino da língua clássica. Em suma, o como ensinar latim muito raramente foi posto em pauta, mesmo naquele momento decisório: a discussão se dava em termos de "manter ou não manter". A batalha pelo humanismo, portanto, se configurava como uma luta entre um espírito de renovação que representavam as disciplinas científicas e exatas, e um espírito conservador, que desejava manter os estudos clássicos como eram, representantes de um status quo social e político. 
Em 1942, com a reforma Capanema, os estudos clássicos ocuparam um lugar privilegiado no currículo: o ensino de latim era destinado a todas as séries do curso ginasial. Segundo Souza, a reforma Capanema foi "o último reduto da língua latina na educação secundária e da valorização da cultura geral como eixo central da formação da juventude" (SOUZA, 2009: 81). Mas esse estado não durou muito tempo: a batalha continuou acirrada, e o desfecho dessa disputa se deu com a promulgação da Lei de Diretrizes e Bases da Educação Nacional em 1961 (Lei 4.024/61), através da qual o latim e outras disciplinas antes obrigatórias, como a filosofia (cf. FAVERO et al., 2004), se tornaram disciplinas optativas. Essa omissão foi o golpe definitivo que levou os estudos clássicos a perderem a sua supremacia no ensino secundário, fazendo com que desaparecessem das práticas escolares.

No âmbito universitário, a supressão do latim e dos estudos clássicos dos currículos secundários também causou grande efeito: não havia mais a necessidade de formar professores de latim, uma vez que a demanda havia diminuído drasticamente. A redução da demanda, somada aos ecos dessa mesma batalha entre humanismo e pragmatismo, agora no currículo superior, não podiam ter resultado diferente: também nos currículos dos cursos superiores o latim e os estudos clássicos foram desaparecendo. Novas disciplinas como a linguística passaram a lutar por espaços antes destinados aos estudos clássicos; o latim em geral se reduziu a dois semestres, quando muito, nos currículos universitários.

No entanto, a disciplina sobreviveu e, de início timidamente, se reformulou: aos poucos as influências das teorias modernas da literatura e da linguagem repercutiram positivamente na área. As décadas de 60 a 80 do século XX foram, em geral, um período de adequação à nova realidade. A partir de meados da década de 80 , intensas discussōes acerca do papel do latim, do grego e dos estudos clássicos na universidade surgem: a própria fundação da Sociedade Brasileira de Estudos Clássicos, em 1985, é indicativo do interesse na manutenção da área e do desejo de discutir novos princípios norteadores das práticas de ensino e pesquisa em 
línguas e literaturas clássicas. Essas discussões amadureceram principalmente a partir de 1995, podendo ser indicado como marco inicial desta nova fase, no que tange à teoria e prática do ensino de língua latina, a publicação da obra "Uma Estranha Língua?”, de Alceu Dias Lima.

\section{ConClusōes}

Como vimos, desde os tempos dos jesuítas podem-se reconhecer duas tradições antagônicas no ensino do latim, fruto do que Pearcy (2010: 192) chama de um conflito entre o humanismo e a filologia. Entre os simpatizantes desta, estão os que defendem o latim como estrutura e os métodos focados na análise sintática e morfológica. Nestes, o principal mérito do estudo do latim está na análise e compreensão dos fenômenos do idioma e na instrumentalização dos alunos para os estudos linguísticos, seja no aprendizado de uma nova língua, numa compreensão mais aprofundada da língua materna, em estudos de etimologia, linguística comparativa e outros campos afins. Já os defensores da postura chamada pelo autor humanista enxergam o latim como veículo de culturas - antiga, medieval, renascentista - e, por objetivarem o acesso aos bens culturais do passado, valorizam a utilização de métodos que propiciem a leitura corrida e a fluência no uso da língua. Neste caso, o principal objetivo do estudo de latim está no arcabouço literário e cultural a ser acessado. Claramente, os fins justificam os meios empregados: os que consideram que o latim é instrumento para a melhor compreensão de fenômenos e estruturas linguísticos devem optar por metodologias centradas no domínio da morfologia e da sintaxe; já os que formam os alunos com vistas à leitura de textos devem buscar metodologias que privilegiam o letramento cultural e a compreensão do contexto. Pearcy (2010:194) vê méritos em ambos os posicionamentos e procura empreender uma análise neutra, concluindo que os professores de latim lecionam diante e a partir da tensão entre essas duas tradições.

Miotti (2004), ao refletir sobre o contexto brasileiro, reconhece o mesmo conflito descrito por Pearcy, mas entende que o ensino de latim deve ter como objetivo o 
desenvolvimento da habilidade de leitura de textos originais de modo a familiarizar os alunos com a história e a cultura da Roma antiga, colocando-se, portanto alinhada à tradição humanística. Os métodos tradicionais de ensino de latim, de cunho gramático-tradutório, foram criticados por Barboza (2001), que elabora uma descrição de pontos de vista e propostas de ensino expostas em prefácios de manuais brasileiros de ensino de latim, tendo selecionado autores do início do século XX - como Milton Valente, Vandick Londres da Nóbrega e Napoleão Mendes de Almeida - e também autores nossos contemporâneos - como Janete Garcia, Antonio Martinez de Rezende e Oswaldo Furlan.

A partir do trabalho de Barboza, podemos exemplificar essa dicotomia no ensino de latim no Brasil durante o século XX. A autora apresenta, entre outros, o prefácio do manual Ludus, do padre jesuíta Milton Valente, de 1949, e observa que, para Valente, o estudo do latim transformará o aluno em um homem culto e de bem, familiarizado com seu próprio idioma - o português - e sua história: Valente faz uma apologia do latim com base no ornamento do espírito e do conhecimento do português através do latim, uma defesa muito próxima daquela que Souza (2009: 75) expõe como característica dos partidários do ensino do latim nos anos 20.

Por outro lado, ao analisar materiais pós-anos 90 , Barboza identifica uma mudança no posicionamento teórico dos profissionais de ensino de latim. O método Introdução à teoria e prática do Latim, de Janete Melasso Garcia, por exemplo, procura se adequar ao breve espaço que o latim ocupa nos currículos, enfatizando a prática da leitura e compreensão de textos latinos. O método Latina essentia, de Antonio Martinez de Rezende, abertamente afirma que o latim não pode ser encarado como uma língua morta e que seu objetivo é possibilitar ao aluno a compreensão de textos clássicos. Ou seja, vários professores atuantes nas universidades brasileiras hoje têm como objetivo o ensino de latim para a leitura e como elemento de acesso à cultura de outros povos e outras épocas, e não mais o ensino de latim como "supralíngua" ou como base para o ensino de línguas modernas. ${ }^{6}$

Barboza conclui em seu estudo que o principal objetivo do ensino de Latim no início do século XXI, como
6. Vários desses pontos de vista e chamados "mitos" sobre o latim são discutidos em FORTES (2010). 
representado pelos materiais didáticos produzidos no Brasil, consiste em resgatar a relevância cultural do latim através do acesso aos textos produzidos por autores clássicos. $\mathrm{O}$ debate acerca dos fins do ensino de latim parece estar se encerrando: é raro hoje encontrar quem defenda que o latim deve ser aprendido como um tipo de ornamento cultural ou como forma de aprender melhor uma outra língua (cf. FORTES, 2010). Precipuamente, entende-se que o latim tem importância na medida em que se deseja entrar em contato com as principais obras literárias, documentos históricos e outras fontes que foram escritas naquele idioma, e que são incontáveis, dado o papel do latim na Europa durante cerca de vinte séculos. Resta-nos ainda, porém, determinar os meios para chegar a este fim, e esta é uma discussão ardente no campo dos estudos clássicos hoje, no Brasil e no mundo. Miotti (2006) chega às mesmas conclusões:

(...) pelo menos no Estado de São Paulo, houve significativa mudança de pensamento e que se está mais consciente da necessidade de adotar métodos mais arejados e de, principalmente, definir com precisão os objetivos do estudo do latim. A ideia de não dissociar língua e literatura predomina, ainda que encerrada em currículos que acabam por isolar, ao menos na terminologia, uma coisa e outra. Ainda persistem certos obstáculos na equação do tempo escasso com os objetivos do ensino, bem como alguma confusão advinda da determinação de metas não equiparáveis: se o propósito de certo curso é dar um panorama geral da estrutura do latim, a estratégia didática será muito diversa daquela exigida se o propósito é permitir acesso aos textos; se essas metas se confundem, a metodologia de ensino e, por consequência, a sua eficácia, ficam comprometidas (MIOTTI, 2006: 94-95, grifos nossos).

Em suma, ainda que pareça haver algum consenso quanto ao objetivo do ensino de latim, a amplitude desse objetivo e o caminho escolhido pelos docentes de língua latina no Brasil hoje para se chegar a este resultado não é o mesmo e, como apontam outros autores, carecem de discussão. É nosso objetivo, como parte final deste trabalho, apresentar essas questões de forma clara e concisa, apontando para os principais caminhos que se apresentam hoje. 
Ainda pouco explorada no Brasil, mas bastante discutida em outras partes do mundo, surge-nos a questão da delimitação do objeto dos Estudos Clássicos. Anteriormente neste trabalho definimos a língua latina como veículo de objetos culturais cuja produção se estende dos séculos II a.C. a XVIII d.C.. No entanto, em muitos dos centros de ensino de latim e nos currículos por eles adotados, somente a produção de fatia bastante restrita desse período é estudada, a saber, a produção da Antiguidade. O latim dos períodos posteriores é pouco ou nada estudado, circundado pelo preconceito de "língua corrupta" ou "produção menor". No entanto, em outras regiōes, já há décadas instaurou-se um movimento de valorização da produção pós-clássica que hoje se reflete nos currículos e nas publicações, que dão igual valor e espaço no currículo ao latim da Antiguidade e dos períodos posteriores. ${ }^{7}$ No Brasil, são em geral isoladas ou de pouco fôlego as iniciativas de estudo de latim pós-Clássico, e não identificamos nenhuma discussão teórica publicada sobre o assunto, dominando os currículos apenas o latim da Antiguidade.

Quanto às metodologias, temos, de um lado, ainda vários docentes que, por inércia, por desconhecimento ou por falta de formação docente adequada, ${ }^{8}$ usam métodos tradicionais, gramático-tradutórios, mesmo que em clara discordância com os ideais ou objetivos professados pelos mesmos docentes. ${ }^{9}$ Maranhão (2009) crítica esse descompasso entre o objetivo declarado e a forma como o latim tem sido ensinado: segundo a autora, o ensino de línguas clássicas está pautado no modelo de conhecimento sistêmico, que concebe a leitura como um processo de decodificação do texto através da interpretação dos elementos linguísticos que possui, uma forma de compreender o aprendizado de línguas estrangeiras que foi há muito substituído no ensino de línguas modernas, por seus resultados ineficazes. No caso do latim, a manutenção desta postura

reduz o seu ensino ao das estruturas linguísticas, desconsiderandose o seu valor comunicativo (e, portanto, socialmente posicionado, com inevitáveis implicaçôes na atribuição de sentido aos textos), e reforça o seu caráter de "línguas mortas", como se a interação não tivesse ocorrido entre autor-leitor na Antiguidade e não se
7. Como exemplo, citemos a universidade de Leuven, uma das pioneiras na área, com a publicação da revista Humanistica Lovaniensia, peroódico anual circulando ininterruptamente desde 1968, dedicada exclusivamente à publicação de estudos sobre obras neolatinas; os currículos da Universidade de Toronto e da Universidade do Kentucky, com cursos destinados a alunos que desejam se especializar em latim medieval e/ou neolatim; a publicação, em 1995, da obra Reading Medieval Latin, de Keith Sidwell, como sequência à famosa obra Reading Latin, do mesmo autor, que vem confirmar o que já fora afirmado pelos autores do volume de 1986: “ Se ignorássemos aquela tradição (do uso e papel do latim na cultura ocidental), e nos concentrássemos estritamente no latim clássico, sentimos que estaríamos privando os alunos de uma compreensão da verdadeira importância do latim para o mundo ocidental." (JONES \& SIDWELL, 1986: v); os livros didáticos da coleção Latin for the New Millenium, de Milena Minkova e Terence Tunberg (2008), metade dos quais são dedicados a obras pós-clássicas; entre muitas outras iniciativas que apontam para uma ampliação dos limites do que se compreende como conhecimento mínimo dentro da área de língua e literatura latina.

8. A questão da formação do docente de latim é igualmente espinhosa e 
ainda menos trabalhada, aguardando tratamento teórico adequado.

9. Esses ideias e objetivos declarados podem ser acessados no trabalho de Miotti (2006) mas foram também por nós analisados durante os debates nos Encontros de Professores de Latim realizados entre 2010 e 2012

(informações em https:// sites.google.com/site/ encontrodeprofessoresdelatim/) e nos questionários com os quais estamos trabalhando para a fase seguinte desta pesquisa.

10. Para mais informaçôes sobre essas metodologias, cf. RICHARDS \& ROGERS (2001), em especial capítulos 1 e 4 .

11. O termo "falantes autênticos" ou "falantes legítimos" para se referir aos falantes de latim como língua materna, que obviamente são apenas os falantes da Antiguidade, excluindo-se os demais como "ilegítimos" ou

"inautênticos", é usado por vários autores que, abertamente ou não, defendem o uso exclusivo de material da Antiguidade, tais como Longo (2008: 155) e BRUNO (1990: 70). pudesse estabelecer entre autor-leitor na atualidade (MARANHÃO, 2009: 30).

De outro lado, metodologias desenvolvidas principalmente a partir de meados do século XX e ditas "de leitura", exemplificadas pelos métodos Reading Latin e Artes Latinae, têm como objetivo expresso treinar a leitura de textos em língua latina para que ela se faça de maneira fluente. Nessas metodologias, em geral devedoras das teorias de ensino aplicadas a línguas estrangeiras modernas tais como a abordagem estrutural ou a audiolingual, ${ }^{10}$ os alunos aprendem através da leitura de textos preparados, que gradualmente passam de frases simples a trechos mais complexos. A habilidade de leitura é desenvolvida através da construção de expectativas textuais, construídas a partir da internalização de estruturas morfossintáticas. No entanto, há grande discordância quanto ao uso deste tipo de metodologia:

a) quanto aos textos utilizados, uma vez que há os que só aceitem que se usem textos ditos autênticos, isto é produzidos por falantes nativos de latim, e não textos criados modernamente como instrumentos didáticos, e há os que apontem as quase intransponíveis dificuldades em se encontrar textos dos ditos "falantes autênticos"11 que não tenham elementos complexos demais para um iniciante;

b) quanto ao ensino da gramática, que, para alguns docentes, fica prejudicado pelo volume de leitura e pela falta de exercícios que se debrucem especificamente sobre a gramática; alguns expressam insatisfação com os resultados do uso deste tipo de material por entender que os alunos não adquirem precisão no domínio das formas;

c) principalmente quanto ao uso do latim como língua ativa, ou seja, quanto ao uso de exercícios de escrita e de oralidade; os primeiros existiam nos métodos tradicionais, mas foram gradualmente abandonados em muitos dos cursos de latim, ainda que subsistam nos centros mais tradicionais, como em Cambridge ou na University of London, ambos na Inglaterra; os últimos, em especial, 
são bastante controversos, mas vem ganhando adeptos desde meados do século XX ao menos na Europa.

Sem dúvida há uma série de teorias e práticas intermediárias, que se apresentam como uma mescla desses diferentes pontos de vista, aproveitando elementos de um e outro, em busca de um melhor equilíbrio. Citemos, a título de exemplo, proposta de Longo (2008) que sugere método do tipo leitura e uso de prática ativa de língua latina, através de perguntas e respostas, procedimento também usado por Sweet (2006) no já referido Artes Latinae.

No Brasil, este assunto está cada vez mais na pauta dos docentes de língua e literatura latina: além da já citada dissertação de Charlene Miotti, as teses de doutoramento de Alzir Oliveira (2008) e José Amarante Santos Sobrinho (2013), por exemplo, são sinais do interesse crescente, no meio acadêmico brasileiro, pelas questóes da docência em línguas clássicas. A continuidade desta pesquisa pretende, a partir da observação empírica e das contribuições dos próprios docentes de universidades públicas brasileiras em todas as regiōes do país, traçar um panorama do ensino de língua latina na universidade pública brasileira, tocando também em questôes metodológicas.

Observa-se, portanto, que, a partir do ano 2000, as reflexões sobre o ensino de língua latina passam a se ocupar também do "como", da forma através da qual a língua deve ser ensinada, atentando para o lugar que o latim ocupa nos currículos e para o objetivo do contato dos alunos do século XXI com essa língua nascida entre as colinas do Lácio há mais de dois milênios. Se, conforme diz Maranhão (2009: 33), o aprendizado de latim deve considerar o "desenvolvimento da habilidade de refletir a língua como fenômeno social, histórico, cultural, político e ideológico, dentre outros", os docentes de língua e literatura latina nas universidades brasileiras buscam ainda as melhores formas de transmitir esse rico legado. 


\section{REFERÊNCIAS BibLIOGRÁFICAS}

ALMEIDA, Anita Correia Lima de. Aulas Régias no Império Colonial Português: o global e o local. In: LIMA, Ivana Stolze; CARMO, Laura do (Org.). História social da lingua nacional. Rio de Janeiro: Casa de Rui Barbosa, 2008. p. $65-90$

BANGERT, William V. História da Companhia de Jesus. São Paulo: Loyola, 1985.

BARBOZA, Gabriela. Reflexões sobre abordagens e manuais de ensino de latim. Ideias. Revista do Curso de Letras. Santa Maria, n. 24, p. 44-49, jul/dez 2007.

BOAVENTURA, Edivaldo M. A educação brasileira no período Joanino. In: A construção da universidade baiana: objetivos, missôes e afrodescendência. Salvador: EDUFBA, 2009, p. 129-141.

BRUNO, Haroldo. Latim e formação linguística. Alfa, São Paulo, n.34, p.69-74, 1990.

FÁVERO, Altair Alberto et al. O ensino da filosofia no Brasil: um mapa das condições atuais. Cadernos CEDES, Campinas, v. 24, n.64, p.257-284, set/dez 2004.

FORTES, Fábio da Silva. A "língua” e os textos: gramática e tradição no ensino de latim. Instrumento, Juiz de Fora, v.12, n.1, p.63-70, jan/jun 2010 .

FRANCA, L. O método pedagógico dos jesuitas: o Ratio Studiorum. Rio de Janeiro: Agir, 1952.

FREIRE, Luiz GL. Educação Jesuítica do século XVI ao XVIII: a memória do espaço e o espaço da memória. Cadernos do CEOM, Chapecó, v. 22, n.31, p. 177-191, 2009.

HARTOG, François. O século XIX e a História: o caso Fustel de Coulange. Trad. Roberto Cortes de Lacerda. Rio de Janeiro: EdUFRJ, 2003.

IJSEWIJN, Jozef. A Companion to Neo-Latin Studies. Volume 1: History and Diffusion of Neo-Latin Literature. 2.ed. rev. Louvain: Leuven University; Peeters, 1990. 
JONES, Peter V. \& SIDWELL, Keith C. Reading Latin: Text. Cambridge: Cambridge University, 1986.

LIMA, Alceu Dias. Uma estranha lingua? Questôes de linguagem e de método. São Paulo: Unesp, 1995.

LONGO, Giovanna. Da fala à língua: proposta de encaminhamento para o estudo do enunciado latino. Anais XXIII SEC, Araraquara, p. 150-157, 2008.

MACIEL, Lizete S.B.; SHIGUNOV NETO, Alexandre. A educação brasileira no período pombalino: uma análise histórica das reformas pombalinas do ensino. Educação e Pesquisa, São Paulo, v.32, n.3, p. 465-476, set./dez. 2006.

MARANHÃO, Samantha de Moura. Reflexões sobre ensino de língua latina em cursos superiores de Letras modernas. Instrumento, Juiz de Fora, v. 11, n. 1, p. 27-36, jan/jun 2009.

MINKOVA, Milena \& TUNBERG, Terence. Latin for the New Millenium. Mundelein, Illinois: Bolchazy-Carducci, 2008. $2 \mathrm{v}$.

MIOTTI, Charlene Martins. O ensino do latim nas universidades públicas do estado de São Paulo e o método inglês Reading Latin: um estudo de caso. 2006. Dissertação (Mestrado em Linguística). Instituto de Estudos da Linguagem (IEL), Unicamp, Campinas, 2006.

MIOTTI, Charlene Martins. Universidades Estaduais Paulistas: o latim na berlinda. Anais do $6^{\circ}$ Encontro Celsul Círculo de Estudos Linguísticos do Sul, novembro de 2004. Disponível em: <http://celsul.org.br/Encontros/06/ Individuais/182.pdf>. Acesso em 15 de março de 2013.

OLIVEIRA, Alzir. O latim, uma língua morta? Uma metáfora em análise. 2008. Tese (Doutorado em Letras). Universidade Federal do Rio Grande do Norte, Natal, 2008.

OSTLER, Nicholas.Ad infinitum: a biography of Latin. New York: Walker, 2007.

PEARCY, T. Lee. Preparing Classicists or Preparing Humanists? Teaching Classical Languages. Spring: 2010, p. 192-195. Disponível em: <http://tcl.camws.org/spring 2010/ TCL_I_ii_Spring_2010.pdf>. Acesso em 15 de março de 2013. 
PEDRO, Lívia. História da Companhia de Jesus no Brasil: Biografia de uma obra. 2008. Dissertação (Mestrado em História). Universidade Federal da Bahia, Salvador, 2008.

RAYMUNDO, Gislene Miotto Catolino. Os princípios da modernidade nas práticas educativas dos jesuitas. 1998. 143p. Dissertação (Mestrado em Educação). Universidade Estadual de Maringá, Maringá, 1998.

RICHARDS, Jack C. \& RODGERS,Theodore S. Approaches and Methods in Language Teaching. $2^{\text {nd }}$. ed. Cambridge: Cambridge University, 2001.

SANTOS SOBRINHO, José Amarante. Dois tempos da cultura escrita em latim no Brasil: o tempo da conservação e o tempo da produção - discursos, práticas, representações, proposta metodológica. Tese (Doutorado em Língua e Cultura) Universidade Federal da Bahia, Salvador, 2013.

SHIGUNOV NETO, Alexandre; MACIEL, Lizete S.B. O ensino jesuítico no período colonial brasileiro: algumas discussões. Educar. Curitiba, n. 31, p. 169-189, 2008.

SIDWELL, Keith C. Reading Medieval Latin. Cambridge: Cambridge University, 1995.

SOLODOW, Joseph B. Latin alive: the survival of Latin in English and the Romance languages. Cambridge: Cambridge University, 2010.

SOUZA, Rosa Fátima de. A renovação do currículo do ensino secundário no Brasil: as últimas batalhas pelo humanismo (1920-1960). Curriculo sem Fronteiras, v.9, n.1, pp.72-90, Jan/Jun 2009.

SWEET, Waldo. Artes Latinae. $2^{\text {nd }} . e d$. Wauconda, Illinois: Bolchazy-Carducci, 1996.

TUNBERG, Terence. De rationibus quibus homines docti artem Latine colloquendi et ex tempore dicendi saeculis XVI et XVII coluerunt. Leuven: Leuven University, 2013. (Supplementa Humanistica Lovaniensia XXXI)

VERNEY, Luís António. Verdadeiro método de estudar. Edição organizada por António Salgado Júnior. Lisboa: Sá da Costa, 1949-1953. 
VOLPILHAC-AUGER, Catherine. La collection Ad usum Delphini: entre érudition et pédagogie. Histoire de l'education. Ecole normale supérieure de Lyon, Mai-1997, numéro 74, 203-214.

Enviado em dezembro de 2013 Aprovado em agosto de 2014. 
